\title{
A new urban soil model for SOLENE-microclimat: review, sensitivity analysis and validation on a car park.
}

\author{
AZAM Marie-Hélène ${ }^{\mathrm{a}, \mathrm{c}, *}$, MORILLE Benjamin ${ }^{\mathrm{a}}$, BERNARD Jérémy ${ }^{\mathrm{a}, \mathrm{b}}$, \\ MUSY Marjorie ${ }^{\mathrm{a}, \mathrm{c}}$, RODRIGUEZ Fabrice ${ }^{\mathrm{a}, \mathrm{d}}$ \\ Nantes, FRANCE \\ ${ }^{a}$ Institut de Recherche en Sciences et Techniques de la Ville, FR CNRS 2488, F-44000 \\ Nantes, France \\ ${ }^{b} U M R$ AAU - CRENAU, Ecole Nationale Supérieure d'Architecture de Nantes, F-44000 \\ Nantes, France \\ ${ }^{c}$ Cerema, F-44000 Nantes, France \\ ${ }^{d}$ Institut français des sciences et technologies des transports, de l'aménagement et des \\ réseaux, F-44000 Bouguenais, France
}

\section{Abstract}

The main purpose of this study is to evaluate an urban soil model that will accurately reproduce the heat flux into urban soil, which has an influence on the urban heat island effect, for typical urban land use such as a car park. After a complete literature review, a sensitivity study is carried out on a large number of parameters: material properties, layer size, deep boundary condition, and convective heat transfer coefficient. The model's ability to reproduce heat conduction transfer is validated via a measurement campaign performed on an asphalt car park during hot days. The mean daily RMSE between estimated and observed surface temperature is $0.86^{\circ} \mathrm{C}$, and $0.72^{\circ} \mathrm{C}, 0.58^{\circ} \mathrm{C}, 0.26^{\circ} \mathrm{C}$ and $0.13^{\circ} \mathrm{C}$ respectively at $5 \mathrm{~cm}-, 10 \mathrm{~cm}-, 34 \mathrm{~cm}-$ and $50 \mathrm{~cm}$-depths. Performances obtained using different node distributions are

\footnotetext{
*Corresponding author. E-mail address: marie-helene.azam@cerema.fr Address: Cerema, 9 rue René Viviani, 44000 Nantes, France
} 
discussed and compared with results from the literature. The model is more efficient than most of the other models applied under similar conditions. Finally, application of the proposed model on a yearly basis demonstrates that the accuracy loss caused by the decrease in the number of nodes is higher for clear and sunny days.

Keywords: Urban soil model, Heat transfer, Soil surface temperature, SOLENE-Microclimat, Urban Heat Island.

\section{Highlights}

- We propose a soil model dedicated to the assessment of climate adaptation strategies.

- Computed surface temperature and temperature at several depths are validated against measurements

- An overall sensitivity analysis of the model parameters is performed

- Different convection flow modes -forced, mixed and natural- are investigated

- The model's performance with optimized mesh is compared with that of the literature 
1

2

3

4

5

6

7

8

\section{Introduction}

In conditions of global warming, the development of cities must be carried out considering the urban heat island (UHI) phenomenon [1] as a serious environmental issue. This phenomenon has several consequences on outside comfort and on building energy needs. In order to mitigate the UHI, it is necessary to identify its causes and to quantify the impact of mitigation solutions. Measurements campaigns are useful to evaluate the UHI, but linking it to the influence of modifications in urban form or urban planning choices is quite tricky.

For this purpose, numerical simulation is a powerful tool. Several models under development simulate the UHI phenomenon and its consequences. Different scales are considered, depending on the application intended: for example TEB [2] or ARPS-VUC [3] are more suitable for city-scale applications while models like SOLENE-microclimat [4], Envi-met [5] and EnviBatE [6] are more appropriate for the district scale.

For a given scale, each tool may have one specific feature among many others: EnviBatE [6] is designed to study the energy demand of a group of buildings, SOLENE-microclimat [4] focuses on outdoor comfort and on the impact of urban climate on indoor comfort, and ENVImet [5] is dedicated to outdoor comfort.

All those models have in common the fact that they represent several physical mechanisms: radiative fluxes, thermal fluxes and fluid dynamics. Furthermore, the representation of these phenomena is essential to accurately calculate the soil surface temperature, which is the key to the interaction between the soil and the urban environment (radiative and sensible fluxes). 
The heat flux stored and released by urban material respectively during dayand night-time is one of the main causes of UHI development. This heat flux is greater in urban than in rural areas due to the high inertia of the materials used. The simulation of heat transfer in facades and in the soil are therefore of the highest importance.

Consequently, there is a need to enhance the ability of urban soil models to simulate heat fluxes in complex heterogeneous urban contexts. The SOLENE-microclimat model (whose efficiency has already been proven) is being developed and validated to answer this need. It is a complex model made up of several modules [7], implying that validation should be performed on each module individually. This article presents one of these validation steps.

The main purpose of this article is to modify and validate the existing SOLENE-microclimat soil model. The modifications are based on a review of the literature and on a sensitivity analysis. Validation is performed using temperature and flux measurement carried out on an open car park.

The open space is chosen to get away from the constraints of an urban environment: diffuse and reflected solar radiation depending on masks, the albedo of the surrounding surfaces, long-wave radiation exchanges with surrounding surfaces, etc.

As the accuracy of the model is often linked to its numerical cost, the additional aim of this study is to develop optimized discretization in order to reach a compromise between accuracy loss and computational efficiency. The results of the study are divided into three parts:

- sensitivity study on model parameters, 
- model validation using a centimetric grid in order to evaluate the model's ability to reproduce conductive heat transfer into the soil,

- calculation of the accuracy loss caused by different node distributions.

The model's performance is then compared to that of models identified in the literature. Finally, performance is analysed for a whole year of simulation.

This exhaustive study provides accurate information about the reliability of the SOLENE-microclimat soil model.

\section{State of the art}

\subsection{Existing models}

In the literature on microclimate models, soil representation is rarely fully described. However, soil models are also used in other fields such as:

- Geothermal energy applications,

- Road applications: pavement sustainability or frost forecasts, - Hydrology and interaction between soil, vegetation, and atmosphere.

Those other domains have the advantage of proposing a different point of view on the way to model heat transfer in the ground. In Table 1 the articles used for the following literature review are shown together with the characteristics of the soil models. 


\begin{tabular}{|c|c|c|c|c|c|c|c|c|c|c|c|c|}
\hline & \multirow{2}{*}{ Article } & \multicolumn{3}{|c|}{ Type of application } & \multicolumn{3}{|c|}{ Surface } & \multicolumn{2}{|c|}{ Type of coating } & \multicolumn{3}{|c|}{ Soil column } \\
\hline & & $\mathrm{B}, \mathrm{GE}$ & Roads & SVA & $\mathrm{UM}$ & Previous & Imprevious & Pavement & Bare-soil & Vegetation & Homogeneous & Heterogeneous \\
\hline & Asaeda and Ca $(1993,[8])$ & & & & $\mathrm{x}$ & $\mathrm{x}$ & & $\mathrm{x}$ & $\mathrm{x}$ & & & $\mathrm{x}$ \\
\hline & Best $(1998,[9])$ & & $\mathrm{x}$ & & & $\mathrm{x}$ & & $\mathrm{x}$ & $\mathrm{x}$ & $\mathrm{x}$ & $\mathrm{x}$ & \\
\hline & Best and al. $(2005,[10])$ & & $\mathrm{x}$ & & & $\mathrm{x}$ & & & $\mathrm{x}$ & & $\mathrm{x}$ & \\
\hline & Bouyer (2009, [4]) & & & & $\mathrm{x}$ & $\mathrm{x}$ & & $\mathrm{x}$ & $\mathrm{x}$ & $\mathrm{x}$ & & $\mathrm{x}$ \\
\hline & Chow and al. (2011, [11]) & $\mathrm{x}$ & & & & $\mathrm{x}$ & & & & $\mathrm{x}$ & irrelevant & \\
\hline & Diefenderfer and al. (2006, [12]) & & $\mathrm{x}$ & & & & $\mathrm{x}$ & $\mathrm{x}$ & & & irrelevant & \\
\hline & Gros et al. $(2015,[6])$ & & & & $\mathrm{x}$ & & $\mathrm{x}$ & $\mathrm{x}$ & & & & $\mathrm{x}$ \\
\hline & Herb et al. $(2008,[13])$ & & & $\mathrm{x}$ & & $\mathrm{x}$ & & $\mathrm{x}$ & $\mathrm{x}$ & $\mathrm{x}$ & & $\mathrm{x}$ \\
\hline & Hermansson $(2004,[14])$ & & $\mathrm{x}$ & & & & $\mathrm{x}$ & $\mathrm{x}$ & & & & $\mathrm{x}$ \\
\hline & Нo $(1987,[15])$ & & & $\mathrm{x}$ & & & $\mathrm{x}$ & $\mathrm{x}$ & $\mathrm{x}$ & & $\mathrm{x}$ & \\
\hline & Jacovides $(1996,[16])$ & $\mathrm{x}$ & & & & $\mathrm{x}$ & & & $\mathrm{x}$ & $\mathrm{x}$ & $\mathrm{x}$ & \\
\hline o & $\operatorname{Lin}(1980,[17])$ & & & $\mathrm{x}$ & & $\mathrm{x}$ & & & $\mathrm{x}$ & & $\mathrm{x}$ & \\
\hline & Masson $(2000,[2])$ & & & & $\mathrm{x}$ & & $\mathrm{x}$ & $\mathrm{x}$ & & & & $\mathrm{x}$ \\
\hline & Milhalakakou and al. (1997, [18]) & $\mathrm{x}$ & & & & $\mathrm{x}$ & & & $\mathrm{x}$ & $\mathrm{x}$ & $\mathrm{x}$ & \\
\hline & Milhalakakou and al. (2002, [19]) & $\mathrm{x}$ & & & & $\mathrm{x}$ & & & $\mathrm{x}$ & $\mathrm{x}$ & $\mathrm{x}$ & \\
\hline & Nowamooz and al. (2015, [20]) & $\mathrm{x}$ & & & & $\mathrm{x}$ & & & & $\mathrm{x}$ & & $\mathrm{x}$ \\
\hline & Ozgener and al. (2013, [21]) & $\mathrm{x}$ & & & & $\mathrm{x}$ & & & $\mathrm{x}$ & & $\mathrm{x}$ & \\
\hline & Qin and al. $(2002,[22])$ & & & $\mathrm{x}$ & & $\mathrm{x}$ & & & $\mathrm{x}$ & & & $\mathrm{x}$ \\
\hline & Saito and Simunek (2009, [23]) & & & $\mathrm{x}$ & & $\mathrm{x}$ & & & $\mathrm{x}$ & & & $\mathrm{x}$ \\
\hline & Swaid and Hoffman (1989, [24]) & & & $\mathrm{x}$ & & & $\mathrm{x}$ & $\mathrm{x}$ & & & & $\mathrm{x}$ \\
\hline & Yang and al. $(2013,[5])$ & & & & $\mathrm{x}$ & $\mathrm{x}$ & & $\mathrm{x}$ & $\mathrm{x}$ & $\mathrm{x}$ & & $\mathrm{x}$ \\
\hline
\end{tabular}

Table 1: Model application and type of soil

B, GE: Buildings, geothermal energy SVA: Interaction soil, vegetation, atmosphere UM: Urban Microclimate 
Even though the field of application is different, all the articles presented have the common objective of predicting surface temperature or ground heat flux. Depending on the application, the physical mechanisms modelled are not the same. In addition to conductive heat flux, moisture flow is often modelled. This is the case for several applications that use bare-soil and vegetation covers $[22,23,13,8]$. This is useful to estimate the water availability for vegetation or to adjust the thermal properties of the soil depending on humidity content. Nevertheless, for impervious surfaces, moisture flux is mostly neglected [13].

The soil model presented in this paper is designed for an impervious surface in an urban environment. Urban grounds are heterogeneous and made up of different layers characterized by large differences in their physical properties. The model must therefore be able to take several layers into account. In the literature, soil is modelled by either a homogeneous or a heterogeneous column. But for a given area, the size of each layer and its physical properties are not accurately known. By simplification, half of the soil models presented here consider a homogeneous column of soil (Table 1). Nevertheless, in order to accurately simulate the conduction flux all along the vertical axis, the soil profile should be consistent with reality, which implies considering a heterogeneous soil.

Thermal properties are either set to experimental data (i.e.: to better represent measurements the albedo is defined as the ratio between incident and reflected solar radiation), or calibrated.

However, the impact of thermal properties has rarely been investigated. 
Best (1998, [9]) and Herb et al. (2008, [13]) studied the influence of material characteristics (diffusivity, specific heat, etc.) on surface temperature. According to Best (1998 [9]) and Herb et al. (2008 [13]), the emissivity and the thermal conductivity of the pavement have the most influence on surface temperature, while the characteristics of the soil underneath have little influence.

In the case of a homogeneous soil column, there are several possibilities for obtaining ground temperature variation. Among others, we may cite analytical solutions (Fourier analysis $[10,11,15,16,18,19,21,24]$ ), the empirical method [11, 12, 19], or even the force-restore method [17].

For a heterogeneous soil column, only the numerical method can be used to accurately estimate surface temperature and ground temperature for several depths. Twelve of the models described use the finite difference method with an implicit scheme, $[8,9,10,4,6,13,14,15,2,22,23$, 5] except Nowamooz et al. (2015, [20]) who use an explicit scheme. The soil model presented in this paper is based on an implicit finite difference method. The following section presents in detail all possible parametrizations in the case of the finite difference method.

\subsection{Parametrization of finite difference models}

For a given problem-solving method, different choices can be made regarding the node distribution (discretization), boundaries and initial conditions (Table 2). 


\begin{tabular}{|c|c|c|c|c|c|c|c|c|}
\hline & \multirow{2}{*}{ Article } & \multicolumn{2}{|c|}{ Upper boundary } & \multicolumn{2}{|c|}{ Convection coeff. } & \multicolumn{2}{|c|}{ Lower boundary } & \multirow[t]{2}{*}{ Initial conditions } \\
\hline & & Temperature & Flux & Forced & Natural & Temperature & Flux & \\
\hline & Asaeda and Ca $(1993,[8])$ & & $\mathrm{x}$ & $\mathrm{x}$ & & $2.5 \mathrm{~m}$ & & $\mathrm{EV}$ \\
\hline & Best $(1998,[9])$ & & $\mathrm{x}$ & $\mathrm{x}$ & & $1.15 \mathrm{~m}$ & & Exponential profile \\
\hline & Best and al. $(2005,[10])$ & & $\mathrm{x}$ & $\mathrm{EV}$ & & & $\mathrm{x}$ & $\mathrm{EV}$ \\
\hline & Bouyer $(2009,[4]$ & & $\mathrm{x}$ & $\mathrm{x}$ & & $2 \mathrm{~m}$ & & Constant value \\
\hline & Gros et al. $(2015,[6])$ & & $\mathrm{x}$ & CFD & & $0.5 \mathrm{~m}$ & & $\mathrm{NI}$ \\
\hline & Herb et al. $(2008,[13])$ & & $\mathrm{x}$ & $\mathrm{x}$ & $\mathrm{x}$ & & $10 \mathrm{~m}$ & $\mathrm{NI}$ \\
\hline \multirow[t]{7}{*}{0} & Hermansson $(2004,[14])$ & & $\mathrm{x}$ & $\mathrm{x}$ & $\mathrm{x}$ & $5 \mathrm{~m}$ & & NI \\
\hline & Но $(1987,[15])$ & & $\mathrm{x}$ & & $\mathrm{x}$ & $\mathrm{x}$ & & Linear or exponential profile \\
\hline & Masson $(2000,[2])$ & & $\mathrm{x}$ & $\mathrm{x}$ & & & $\mathrm{x}$ & $\mathrm{NI}$ \\
\hline & Nowamooz and al. (2015, [20] & $\mathrm{x}$ & & irrelevan & & $4 \mathrm{~m}$ & & $\mathrm{EV}$ \\
\hline & Qin and al. $(2002,[22])$ & & $\mathrm{x}$ & $\mathrm{x}$ & & $\mathrm{x}$ & & $\mathrm{EV}$ \\
\hline & Saito and Simunek $(2009,[23])$ & & $\mathrm{x}$ & $\mathrm{x}$ & & $\mathrm{x}$ & & $\mathrm{EV}$ \\
\hline & Yang and al. $(2013,[5])$ & & $\mathrm{x}$ & CFD & & $2 \mathrm{~m}$ & & $\mathrm{EV}$ \\
\hline
\end{tabular}

Table 2: Parametrization of finite difference models

EV: Experimental values NI: No Information CFD: Computational Fluid Dynamics 


\section{Vertical discretization}

Depending on the author, different vertical discretizations are used. Ho (1987, [15]) and Qin et al. (2002, [22]) propose uniform layout nodes, whereas

most of the articles present a denser node distribution near the surface than deeper in the ground. Saito and Simunek (2009, [23]) use a denser distribution near the surface and also near the interface between two layers. However, the choice of node distribution is rarely clearly justified. Only Best et al. (2005 [10]) studied the behaviour and accuracy of the model for different vertical discretizations, comparing the numerical solution with the analytical one. The present study also aims to perform a sensitivity analysis on the discretization in order to know how much accuracy is lost when reducing the number of nodes. Few sensitivity studies have been performed on this point. Asaeda and Ca $(1993,[8])$ studied the influence of grid size. As expected, the thinner the resolution of the grid, the more precise the surface temperature. But this accuracy gain is obtained to the detriment of calculation duration. So as Best et al. (2005 [10]) suggested, a compromise should be found between accuracy and execution time.

\section{Boundary conditions}

To solve one dimension heat conduction equation with the finite difference method, two boundary conditions are required. The bottom condition taken at a defined depth can either be a zero flux or a constant temperature (Table 2 ). If the simulation concerns a short period and the last node of the grid is below the diurnal amortization depth, the type of condition has little 
influence on the surface temperature [9].

As the purpose of most articles is to predict surface temperature, the upper boundary condition is defined by the surface energy balance. This balance is composed of radiative fluxes, the sensible flux, the latent flux, and the conductive heat flux into the soil. The long and short-wave radiation fluxes are always calculated, except for the validation process for which measurements are used whenever they are available.

As urban soils have a low albedo, the temperature gradient between the surface and the air can be very great, especially during clear days. This phenomenon leads to natural convection (driven by buoyancy forces). Nevertheless, in the surface energy balance, most authors only take into account the forced convective mode (driven by wind forces), whereas Herb et al. (2008, [13]) proposes considering both forced and natural modes.

Both Hermansson (2004, [14]) and Herb et al. (2008, [13]) assumed that the method used to calculate the convective heat transfer coefficient is a critical point. To test this assumption, they both carried out a sensitivity study on the coefficients of an empirical formula. Herb et al. (2008, [13]) show that the modification of convection parameters can sometimes have a significant impact on surface temperature: for a $10 \%$ increase in the convection parameters, the average surface temperature variation is about $0.24^{\circ} \mathrm{C}$. This might be explained by low wind speed and by a high-temperature gradient between the surface and the air. Hermansson (2004, [14]) dissociates winter and summer periods since the temperature gradient between the surface and the air is smaller during winter. He proposes to use two sets of parameters 
regarding solar radiation conditions. Depending on the season, convection losses and wind velocity are balanced by coefficients.

\section{Initial conditions}

In general, little information is given on the initial conditions (temperature profile) except for the validation process. Most authors use experimental values (Table 2). When this information is not available, several alternatives are proposed: a constant temperature profile $[4,15]$ or an exponential profile between the deep soil and the surface is set $[9,15]$. However, according to (1987, [15]), this parameter has little impact on surface temperature

\section{Methodology of the study}

\subsection{Description of the proposed soil model}

The soil model presented in this paper is designed for an impervious surface such as a pavement coating. Only heat transfer is therefore taken into account (moisture transfer is neglected). The soil model is 1-D, defined as a one-dimensional soil column where each layer has its own characteristics. In an unsteady state, temperature fluctuation is calculated from Equation 1, which is an application of the heat equation for a one-dimensional problem.

$$
\frac{\partial T}{\partial t}=\alpha_{s o i l} \cdot \frac{\partial^{2} T}{\partial x^{2}}
$$

$\alpha_{\text {soil }}:$ thermal diffusivity of the soil $\left[\mathrm{m}^{2} \mathrm{~s}^{-1}\right]$ 
191

192

The problem is solved by a finite difference method using an electrical analogy. Heat resistances represent the resistance to heat transfer through a ground layer and heat capacities, the heat storage capacity of a ground layer. They are defined in Figure 1.

The soil model is composed of $n$ nodes. The energy balance equation is calculated at the surface (node $\mathrm{i}=0$, Equation 2), and then for each following node $i \in] 0: n-1$ ] (Equation 3) until the last one which includes the bottom boundary condition $(i=n$, Equation 4$)$.

$$
\frac{T_{\text {surface }}-T_{\text {air }}}{R_{c}}+\frac{T_{\text {surface }}-T_{1}}{R_{1}}+C_{e} \frac{d T_{\text {surface }}}{d t}=R_{\text {net }}-L E
$$

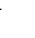

$$
\frac{T_{i}-T_{i-1}}{R_{i}}+\frac{T_{i}-T_{i+1}}{R_{i+1}}+C_{i} \frac{d T_{i}}{d t}=0
$$

102

$$
\frac{T_{n}-T_{n-1}}{R_{n-1}}+\frac{T_{n}-T_{\infty}}{R_{n}}+C_{i} \frac{d T_{n}}{d t}=0
$$

$R_{n e t}:$ net radiation $\left[W \cdot m^{-2}\right]$

$L E$ : latent heat flux $\left[W \cdot m^{-2}\right]$

$H$ : sensible heat flux $\left[W \cdot m^{-2}\right]$

$C_{e}$ : heat capacity of the surface layer $\left[J \cdot m^{-2} \cdot K^{-1}\right]$

$C_{i}$ : capacity of the layer at the node i $\left[J \cdot m^{-2} \cdot K^{-1}\right]$

$R_{c}$ : convection resistance $\left[\mathrm{m}^{2} . K . W^{-1}\right]$

$R_{i}$ : heat resistance of the layer between the node $i-1$ and $i\left[m^{2} . K . W^{-1}\right]$

$T_{\text {surface: }}$ : surface temperature $[K]$

$T_{\text {air }}$ : air temperature $[K]$

$T_{i}$ : temperature of the node i $[K]$ 


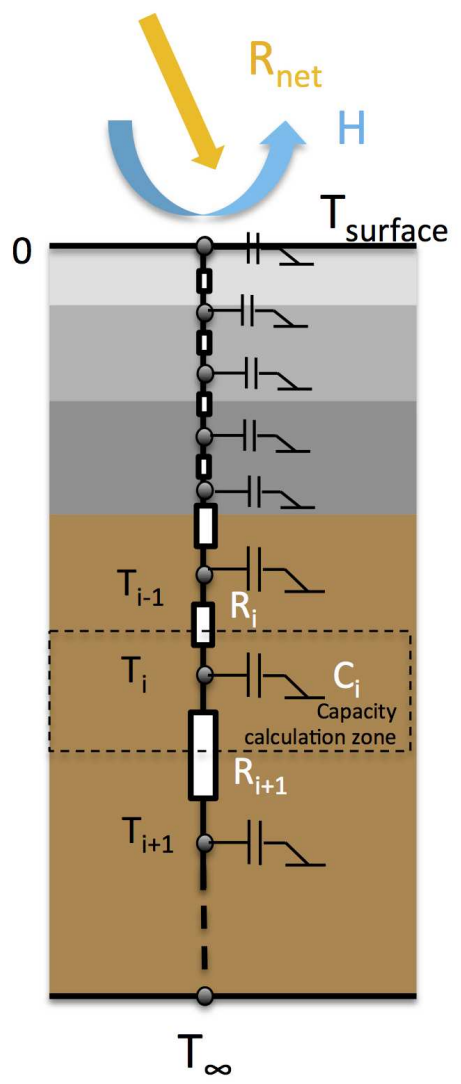

Figure 1: Schematic representation of the soil model: representation of node distribution, heat resistances and capacities, description of a common cross-section of an urban soil column with diffusive material layers in shade of grey and underneath natural soil in brown (1 column, print in color)

According to this method, any node distribution and any boundary condition depth may be used. Most of the authors $[8,9,10,5]$ in the literature work with a centimetric grid when accuracy is required. A model with one node per centimetre is used (see Section 3.1.3).

The top node is located at the ground surface and the deepest one at a depth of $1 \mathrm{~m}$. At this depth, the temperature is supposed to be constant over 
a day. A new value will be set for each day. More details are given in Section 3.1.1.

Figure 1 illustrates the way thermal properties are defined. Each layer of material is assumed to be homogeneous and isotropic and has its own characteristics which are considered to be constant over time.

As the node distribution is defined aside from the soil layers and characteristics, the nodes are not automatically located at the interface between two layers.

\subsubsection{Deep boundary condition}

In deep soil, the temperature is taken to be constant over a day. In the case of homogeneous soil, an analytic solution can be used to calculate the temperature for any depth $z$ and any time step $t$. If the surface temperature is considered to be sinusoidal, the analytic solution follows Equation 5. The parameters $T_{m a}, A_{a}$ and $t_{0}$ are respectively the mean, the amplitude, and the phase of a day surface temperature signal.

$$
T(z, t)=T_{m a}+A_{a} \cdot \exp \left(-\frac{z}{z d_{a}}\right) \sin \left(w_{a}\left(t-t_{0}\right)-\frac{z}{z d_{a}}\right)
$$

$T_{m a}$ : mean annual temperature $\left[{ }^{\circ} \mathrm{C}\right]$

$A_{a}$ : annual half amplitude of the climatic thermal wave at the surface $\left[{ }^{\circ} \mathrm{C}\right]$ $z d_{a}$ : damping depth with an annual beat $[m]$

$w_{a}$ : annual beat $w_{a}=2 * \pi / 31536000\left[\mathrm{rad}_{\mathrm{s}} \mathrm{s}^{-1}\right]$

$t_{0}$ : day of the year where the surface temperature was the coldest 
From a certain depth, the daily signal is completely damped. The damping depth depends on the soil characteristics through the parameter $z_{d a}$, defined by Equation 6. The depth from where the signal is damped at 95 or $99 \%$ can be estimated from Equation 7 .

$$
z_{d a}=\sqrt{\frac{2 . \alpha_{s o l}}{w_{a}}}
$$

$$
A(z)=A_{j} \cdot \exp \left(\frac{-z}{z_{d a}}\right)
$$

$A_{j}$ : half daily amplitude of the climatic thermal wave at the surface $\left[{ }^{\circ} \mathrm{C}\right]$

For a range of materials (asphalt, concrete, bare-soil), the most diffusive is marble. For this material, the depth corresponding to a daily damping of $99 \%$ is $0.89 \mathrm{~cm}$. Beyond a meter in depth, the temperature is assumed to be constant throughout the day whatever the type of ground. For this reason, the bottom node is located below this depth.

\subsubsection{Upper boundary: Heat flux across a ground surface}

The upper boundary condition is defined by the energy balance at the ground surface (Equation 8).

$$
R_{\text {net }}=Q_{\text {cond }}+H+L E
$$

with $R_{\text {net }}, Q_{\text {cond }}, H, L E$ previously defined.

\section{Radiative flux}


The net radiative flux is the balance of all radiative fluxes at the soil surface. It is the sum of short-wave radiation and long-wave radiation. The historical SOLENE radiative model computes radiative transfers, including long-wave radiation, inter-reflexion and shading effects [7]. So this input data does not need to be calculated in future simulations.

\section{Convective heat flux}

The heat flux exchanged between the surface and a moving fluid can be expressed with the Equation 9:

$$
H=h_{c}\left(T_{\text {air }}-T_{\text {surface }}\right)
$$

$h_{c}:$ convective heat transfer coefficient $\left[W \cdot m^{-2} \cdot K^{-1}\right]$

$T_{\text {air }}$ : air temperature $[K]$

$T_{\text {surface }}$ : surface temperature $[K]$

In order to calculate this flux, the convective heat transfer coefficient is required. In the literature, this coefficient is always a function of wind speed. Linear or power law functions are used, or correlations using dimensionless numbers ([25], [26]). For urban applications, the first solution is often used.

The simplest is a linear relation of the wind speed (Equation 9). Depending on the situation (i.e. surface texture, wind velocity, windward/leeward surface, etc.), Palyvos (2008, [25]) suggests around forty combinations for $a$ and $b$ coefficients. For a horizontal surface, with low winds $\left(V_{a i r}<5 \mathrm{~m} / \mathrm{s}\right)$, several coefficients are proposed (Table 3).

$$
h_{c}=a+b * V_{a i r}
$$


269

270

\begin{tabular}{lll}
\hline Reference & $\mathbf{a}$ & $\mathbf{b}$ \\
\hline McAdams (1954, [27]) & 5.7 & 3.8 \\
ASHRAE (1993) & 5.62 & 3.9 \\
Cristofari et al. (2006) & 5.67 & 3.86 \\
\hline
\end{tabular}

Table 3: Coefficients $a$ and $b$ for a flat surface low wind speed

271 Methods based on correlations that use dimensionless numbers (Reynolds, 272 Grashof, and Nusselt) also exist. For flat surfaces Morille (2012, [28]) presents 273 coefficients depending on the flow regime (Table 4).

\begin{tabular}{llllllll}
\hline Convection mode & Flow regime & $a$ & $b$ & $c$ & $d$ & $e$ & $f$ \\
\hline \multirow{2}{*}{ Free } & laminar & 0 & 0 & 0.49 & $1 / 4$ & 1 & 1 \\
& turbulent & 0 & 0 & 0.13 & $1 / 3$ & 1 & 1 \\
\hline \multirow{2}{*}{ Mixed } & laminar & 1 & $3 / 2$ & 0,57 & $3 / 5$ & 0,68 & $1 / 3$ \\
& turbulent & 1 & $12 / 5$ & 12,1 & 1 & 0,03 & $1 / 3$ \\
\hline \multirow{2}{*}{ Forced } & laminar & 0,56 & $1 / 2$ & 0 & 0 & 1 & 1 \\
& turbulent & 0,03 & $4 / 5$ & 0 & 0 & 1 & 1 \\
\hline
\end{tabular}

Table 4: Coefficients as a function of the convection mode for a flat surface

$$
N u=e\left(a R e^{b}+c G r^{d}\right)^{f}
$$


274

$$
N u=\frac{h_{c} \cdot L_{c}}{\lambda_{\text {fluid }}}
$$

Re: Reynolds number

Gr: Grashof number

$N u$ : Nusselt number

$L_{c}$ : characteristic length $[\mathrm{m}]$

$\lambda_{\text {fluid }}$ : thermal conductivity of the fluid $\left[W \cdot m^{-1} . K\right]$

This type of correlation can be used to define a convective heat transfer coefficient as a function of the flow modes:

- Natural or free convection: air flow driven by buoyancy forces,

- Forced convection: air flow driven by wind forces,

- Mixed convection: when the air flow is created by both wind and buoyancy forces.

In the case of urban applications, wind speed is often low and the temperature gradient great. Free convection may then become predominant. A comparison between the MacAdams formula and the correlation method is made in order to choose the most suitable method for an urban climate application (Section 4.1.1).

\subsubsection{Node distribution}

Authors in the literature work with centimetric grid when accuracy is required $([8,9,10,5])$. In order to gauge the accuracy of the proposed grid 

between the analytic solution and the finite difference model.

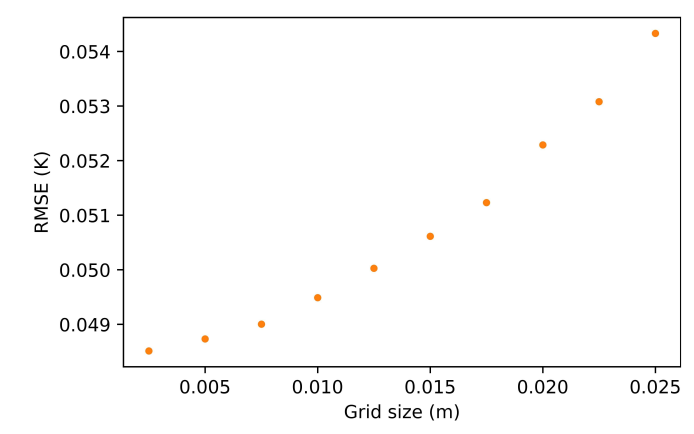

Figure 2: Changes in RMSE for different grid sizes(1 column, print in color) homogeneous soil of asphalt-concrete $\left(\alpha=1.04 * 10^{-6} m^{2} \cdot s^{-1}\right)$.

The analytic solution is compared to a finite difference model with a sinusoidal temperature signal imposed at the surface (Equation 13). The bottom boundary condition is taken as a fixed temperature equal to the mean annual temperature. The model is initialized with a temperature profile calculated by the analytic solution. The simulation is run for 6 days with a time step of 900 seconds.

$$
T_{s}(t)=T_{m a}+A_{a} \cdot \sin \left(w_{a}\left(t-t_{0}\right)\right)
$$

Different grid sizes are tested from $0.0025 \mathrm{~m}$ to $0.025 \mathrm{~m}$ with steps of $0.0025 \mathrm{~m}$. For each grid size, the RMSE is calculated at the last time step,
305

different grid sizes are compared to the analytic solution (Equation 5) for a

306 Figure 2 shows changes in the RMSE for different grid sizes(from 0.0025 to $0.025 \mathrm{~m})$. As expected, the RMSE increases when the grid size increases. The 
benefits of increasing the grid from $0.005 \mathrm{~m}$ to $0.01 \mathrm{~m}$ improved the RMSE by only $0.0009^{\circ} \mathrm{C}$. A model with one node per centimetre is used as a reference.

\subsection{Presentation of the measurement campaign}

The measurement campaign provided data that are used either as model inputs or as validation data to evaluate the performance of the model and its accuracy.
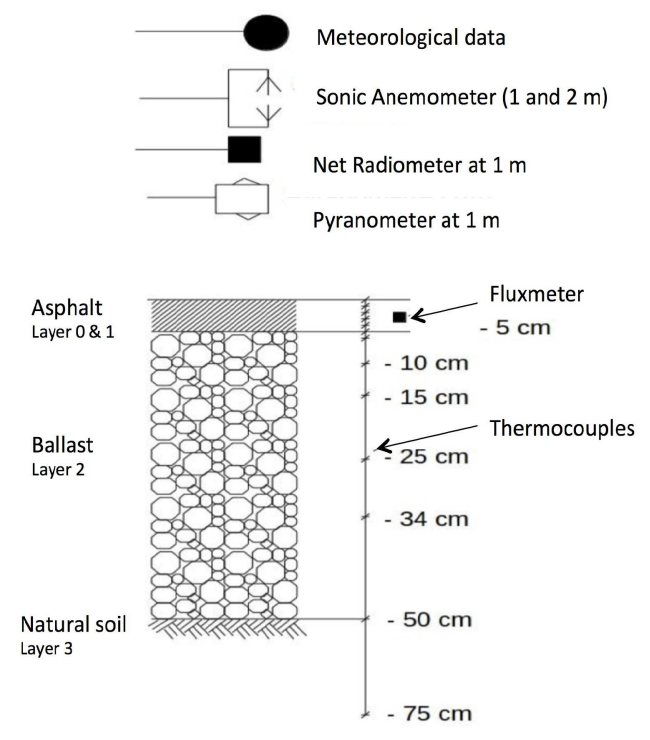

(a) Drawing of the instruments used during the campaign (see Table 5 for a description of the instruments) and crosssection of the soil composition (see Table 6 for the material properties)

(b) View of the experimental site (a $2,500 \mathrm{~m}^{2}$ asphalt car park) with the instruments

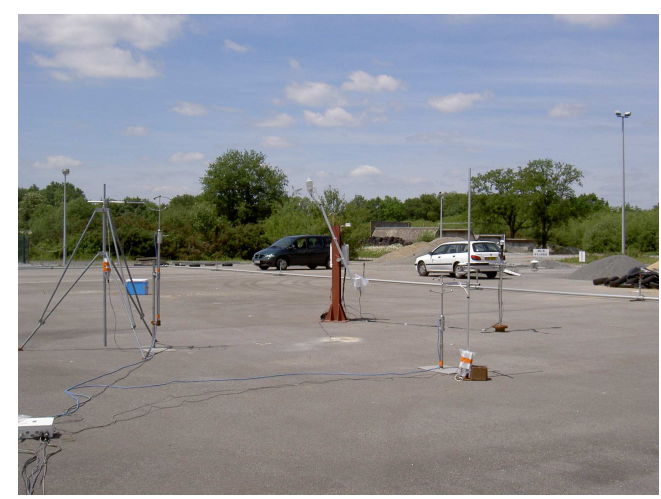

Figure 3: Illustration of the ROSURE measurement campaign 
Data from the ROSURE/HydroVille project are used [29]. This project was led by IFSTTAR and funded by the National Institute for Earth Sciences and Astronomy (INSU) of the Centre National de la recherche scientifique (CNRS). A campaign devoted to the documentation of energy and water budgets of an asphalt car park was carried out in the month of June 2004. This campaign especially focused on surface and air temperatures and on heat flux measurements during a warm summer period. Artificial rain events were created during the campaign but the present study focuses only on dry weather periods.

The experiment site is located near Nantes (France) within the IFSTTAR center of Bouguenais, and consisted of a $2,500 \mathrm{~m}^{2}$ asphalt car park (Figure $3(\mathrm{~b})$ ). The soil structure is composed of a $5 \mathrm{~cm}$ - asphalt layer, a $45 \mathrm{~cm}$ - ballast layer and an altered mica-schist natural soil underneath. Throughout the observations available for this campaign, this study focuses on the following variables, all observed in the middle of the car park described in the Table 5 and in Figure 3(a):

- surface and ground temperatures: vertical profile at depths of $0,1,10$, $3,4,5,6,10,15,104,34,50$ and $75 \mathrm{~cm}$;

- wind speed and direction;

- humidity and air temperature;

- convective heat fluxes;

- radiation components. 


\begin{tabular}{|c|c|c|c|}
\hline Physical quantity & Instrument type & $\begin{array}{l}\text { Height } \\
(\mathrm{m})\end{array}$ & $\begin{array}{l}\text { Measured } \\
\text { variable }\end{array}$ \\
\hline Temperature profile & $\begin{array}{l}\text { thermocouples type } \mathrm{T} \text { (diameter } \\
120 \mu \mathrm{m})\end{array}$ & 0 to -0.75 & $T(z)$ \\
\hline $\begin{array}{l}\text { Wind speed and direc- } \\
\text { tion }\end{array}$ & Young Campbell (05103) monitor & 1.5 & $v$ \\
\hline $\begin{array}{l}\text { Humidity and air tem- } \\
\text { perature }\end{array}$ & $\begin{array}{l}\text { HMP45C TRH probes (Campbell) with } \\
\text { Vaisala HR HUMICAP }\end{array}$ & 1 and 2 & $T, H_{R}$ \\
\hline Soil heat flux & Fluxmeter HFP01 Huskflux & -0.03 & $G$ \\
\hline Short wave radiation & 2 pyranometers CM6B (Kipp \& Zonen) & 1 & $R_{s} \downarrow, R_{s} \uparrow$ \\
\hline Long wave radiation & 2 pyranometers CGR3 (Kipp \& Zonen) & 1 & $\begin{array}{l}R_{I R} \quad \downarrow \\
R_{I R} \uparrow\end{array}$ \\
\hline Net radiation & Radiometer NRLite (Kipp \& Zonen) & 1 & $R_{n}$ \\
\hline Convective heat flux & Sonic Anemometer USA1 (Metek) & 1 and 2 & $\mathrm{H}$ \\
\hline
\end{tabular}

Table 5: Captor used and the corresponding measures 
The data were collected with a 1 min time step except for the sonic anemometer $(0.1 \mathrm{~s})$. The final data were averaged to 15 min time steps. From the whole measurement period, only days without artificial precipitation were used. Four days were selected with different meteorological conditions: three sunny days with scattered clouds (June $5^{\text {th }}, 12^{\text {th }}, 13^{\text {th }}$ ) and one clear sky day (6 $6^{\text {th }}$ of June). The clear sky day was used to calibrate the model ( $6^{\text {th }}$ of June) while the other days were used to evaluate the model (June $5^{\text {th }}, 12^{\text {th }}, 13^{\text {th }}$ ). The meteorological conditions are presented in Figure 4 and Figure 5.

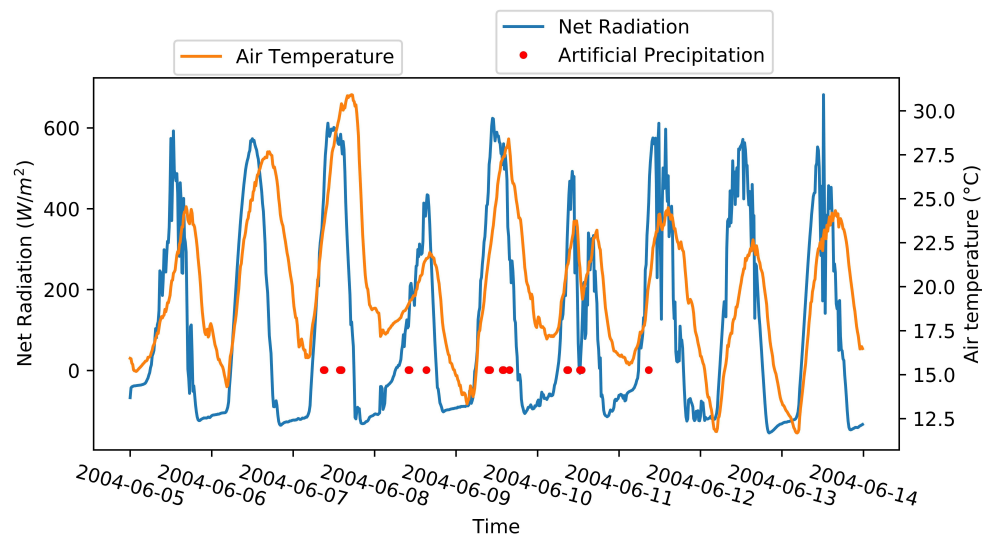

Figure 4: Net Radiation measured at a height of $1 \mathrm{~m}$ and Air Temperature measured at a height of $2 \mathrm{~m}$ from June $5^{\text {th }}$ to $14^{\text {th }}$ (2 columns, print in color) 


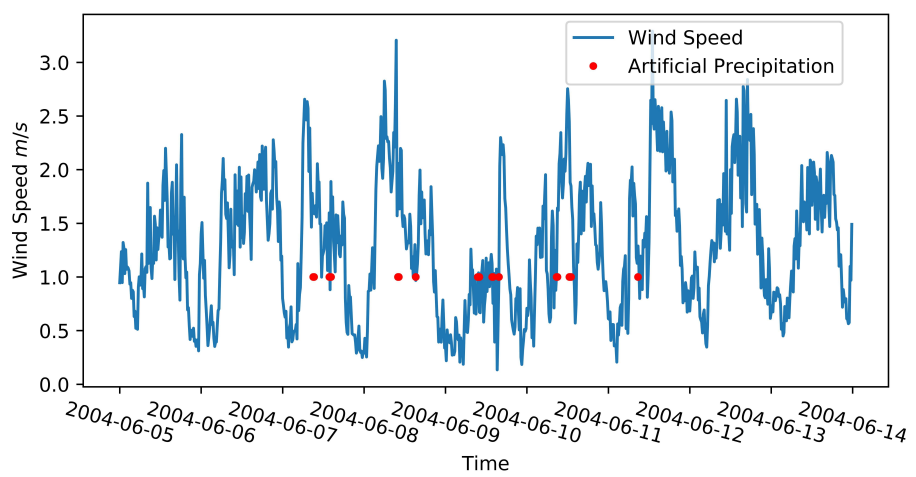

Figure 5: Wind speed measured at a height of $1.5 \mathrm{~m}$ from June $5^{\text {th }}$ to $14^{\text {th }}$ of June (2 columns, print in color)

\subsection{Soil model setup}

In order to model the car park described above, the model parameters need to be set for the current situation.

\subsubsection{Deep boundary condition}

The deep boundary condition is calculated from Equation 5. The value for each of the parameters $\left(T_{m a}, A_{a}\right.$ and $\left.t_{0}\right)$ is set according to air temperature signals. The values used, derived from measurements recorded over 4 years in three locations of the city of Nantes (France). The mean annual temperature is $T_{m a}=2.50^{\circ} \mathrm{C}$, the yearly half amplitude of the daily mean temperature is $A_{a}=1.86^{\circ} \mathrm{C}$ and the phase shift $t_{0}=0$ days.

\subsubsection{Upper boundary condition}

The measurement campaign provided data that are used as model inputs for the calculation of the surface energy balance on the upper boundary condition (Equation 8). 
The sensible heat flux is calculated from the measured air temperature. For the radiative budget measurements are used. Latent heat flux is not considered for now, as in this step of the model only dry days are modeled. In Equation 8, $L E=0$.

\subsubsection{Calibration of the material' properties}

As seen before, the thermal characteristics of the soil are often unknown and must be adjusted to properly represent fluxes and temperatures variations. The characteristics of the soil layers are calibrated according to the observed soil profile, reducing the difference between the measured and simulated surface temperature, with the centimetric grid. Data acquired on June $6^{\text {th }}$ are used for calibration.

The temperature profile is initialized from ground temperatures measured on June $6^{\text {th }}$ at midnight. The deep boundary condition, corresponding to the ground temperature at a depth of $75 \mathrm{~cm}$ is set according to experimental data. At the surface, the boundary condition is calculated from the energy balance with the measured radiative heat flux and calculated convective heat flux (with correlation method formula and a characteristic length of $1 \mathrm{~m}$, see: Section 4.1.1 and Figure 8).

Albedo and emissivity of the surface are calculated from short and long wave radiations measured during the period of interest. For the albedo, the mean diurnal value is 0.173 (for reflected short-wave radiation flux $K_{u p}>$ $20 W \cdot m^{-2}$ ), and the mean emissivity value over the period is 0.965 . 
Soil composition and thermal properties are not known with any accuracy. Their values were not measured during the campaign. As a result, only approximate soil composition was available. Cohard et al. (2017, [29]) tried to estimate the first layers characteristics from the temperature and the ground heat flux measurement. They obtained the following thermal diffusivity $\alpha=1.04 * 10^{-6} \mathrm{~m}^{2} \cdot \mathrm{s}^{-1}$ for a fixed capacity (with $\rho=920 \mathrm{~kg} \cdot \mathrm{m}^{-3}$ and $C p=$ $\left.2050 \mathrm{~J} . \mathrm{kg}^{-1} \cdot \mathrm{K}^{-1}\right)$. The resulting thermal conductivity is $1.96 \mathrm{~W} \cdot \mathrm{m}^{-1} \cdot \mathrm{K}^{-1}$.

From the measured temperature gradient, changes in the soil thermal properties within the first layer were identified $(0-1 \mathrm{~cm}, 1-5 \mathrm{~cm})$. The total capacity of the first layer was then estimated with the surface energy budget measured, the ground heat flux measured at $3.5 \mathrm{~cm}$ and the temperature gradient. The thermal characteristics were then adjusted by an iterative procedure reducing the difference between the measured and the simulated temperature at the surface and various depths. The thermal characteristics values were considered acceptable when the RMSE on each ground temperature had the same level of magnitude as the uncertainty of the sensor $\left(0.2^{\circ} \mathrm{C}\right)$.

The calibrated material characteristics are summarized in Table 6 .

As the material properties were calibrated with the calculated convective heat flux, the proposed thermal properties compensate for the error between the calculation and measurement of the convective heat flux. For this reason the thermal conductivity proposed $\left(2.5 W \cdot \mathrm{m}^{-1} \cdot \mathrm{K}^{-1}\right)$ is greater than that estimated from Cohard et al. (2017, [29]).However, Xu et al. (2010, [30]) point out that the thermal conductivity of asphalt concrete can vary from 0.74 to 


\begin{tabular}{|c|c|c|c|c|}
\hline Layer & Material & Depth & $\begin{array}{l}\text { Thermal } \\
\text { conductivity }\end{array}$ & $\begin{array}{l}\text { Volumetric } \\
\text { heat capacity }\end{array}$ \\
\hline Number & Characteristics & $\mathrm{m}$ & $W \cdot m^{-1} \cdot K^{-1}$ & $10^{6} J \cdot m^{-3} \cdot K^{-1}$ \\
\hline 0 & Asphalt Concrete & 0.01 & 2.5 & 2.3 \\
\hline 1 & Asphalt Concrete & 0.05 & 2.5 & 2.1 \\
\hline 2 & Old Filled Ballast & 0.5 & 1.8 & 2.3 \\
\hline 3 & $\begin{array}{l}\text { Altered Mica-schist } \\
\text { Natural Soil }\end{array}$ & 1 & 1.3 & 2.1 \\
\hline
\end{tabular}

Table 6: Calibrated characteristics of the soil

$2.88 W \cdot m^{-1} \cdot K^{-1}$, diffusivity ranges from $4.4 * 10^{-7}$ to $14.4 * 10^{-7} m^{2} \cdot s^{-1}$, and specific heat from 879 to $1364 J . \mathrm{kg}^{-1} . \mathrm{K}^{-1}$.

Yang et al. (2013, [5]) noticed that thermal characteristics of the asphalt layer may vary with depth. Due to asphalt compaction, the layer density and the asphalt proportion are not constant along the depth, altering the thermal properties. Yang et al. (2013, [5]) chose to divide the asphalt layer into several layers to which different properties were attributed. The same phenomenon is observed through analysis of the temperature signal within the asphalt layer. For this reason, the asphalt layer is divided into two layers (of $1 \mathrm{~cm}$ and $4 \mathrm{~cm}$ respectively).

After calibration, the model correctly reproduces the conducted heat flux into the different layers of the soil as shown in Figure 6. 


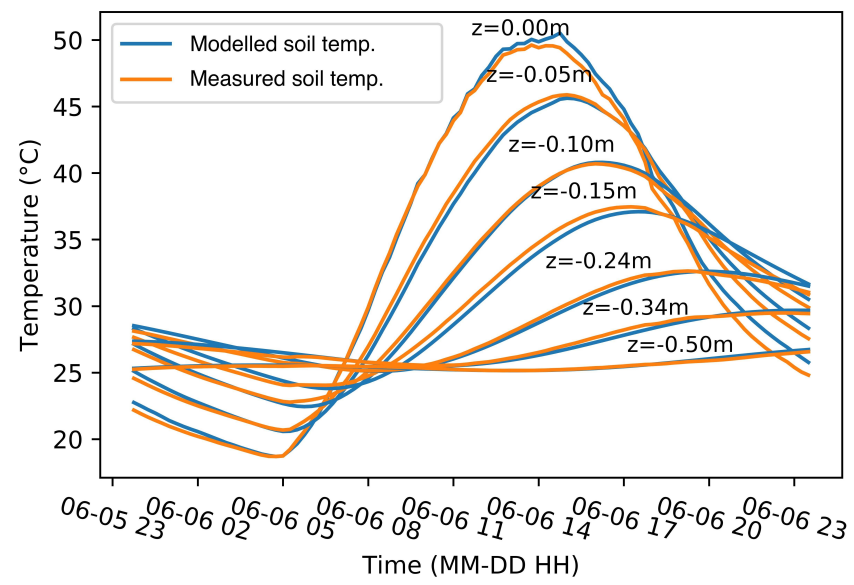

Figure 6: Comparison of simulated and measured temperatures at the surface and at several depths on June $6^{\text {th }}$ (1 column, print in color)

\subsection{Model performance assessment}

Several indicators may be used to evaluate the performance of a soil model. Most authors focus on the ability of their model to estimate surface temperature. Only a few of them go further in the analysis evaluating the heat flux calculation or the ground temperature at different depths.

In this article, the indicator chosen is the RMSE (Root Mean Square Error). As the authors used this, it will be easier to compare model accuracy. In order to determine whether the dynamics of heat storage are properly reproduced, the RMSE will be calculated at the surface and at several depths.

\subsection{Node distribution definition methodology}

Optimization of the node distribution represents a major challenge. The principle consists in reducing the number of nodes until a situation is reached where calculation time and lack of accuracy are minimal. 


\begin{tabular}{lll}
\hline Zone & $\begin{array}{l}\text { Depth of the } \\
\text { part }[m]\end{array}$ & Criterion \\
& & $\begin{array}{l}\text { Amortization depth for the material with the } \\
\text { highest diffusivity and three hourly pulsa- } \\
\text { tions }\end{array}$ \\
& 0.08 & Amortization at $95 \%$ of the daily signal for \\
& & the most common material for this part ( soil, \\
& & concrete, stone) \\
3 & & Amortization at $95 \%$ of the daily signal for \\
& & the material with the highest diffusivity
\end{tabular}

Table 7: Criterion for the choice of size for each zone

For grid optimization, the choice was made to work with annual simulation. First, an analytic solution is used to better understand ground temperature dynamics. In this way, two sinusoidal temperature signals are applied to the surface: a three-hour period (corresponding to weather change or shadows created by buildings during a day) and a day period (corresponding to the day-night cycle). The profiles obtained from the analytical solution are presented on the right-hand side of Figure 7. The closer we get to the deep condition, the more linear the profile. With the finite difference method, the more linear the profile, the less dense the distribution of nodes needs to be. According to this result, node distribution is different in the three zones: the criteria used to identify each of them are given in Table 7.

Three node distributions are then proposed to better represent these ground temperature profiles (Figure 7). The final distribution profiles are 
Node distributions :

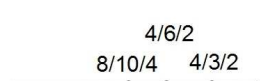

consistent with those proposed in the literature: the node density is higher in the upper layer of the ground than in the lower layers.
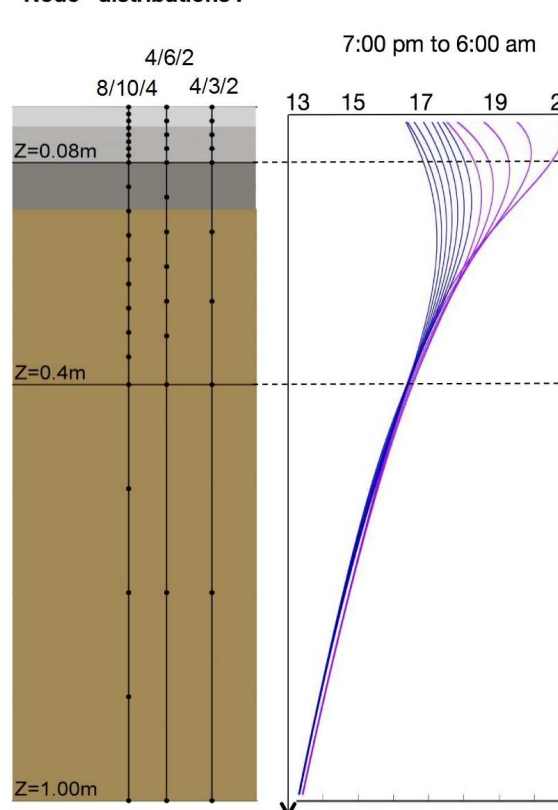

Soil temperature profiles $\left({ }^{\circ} \mathrm{C}\right)$ :

7:00 am to $10: 00 \mathrm{am} \quad 11: 00 \mathrm{am}$ to $6: 00 \mathrm{pm}$

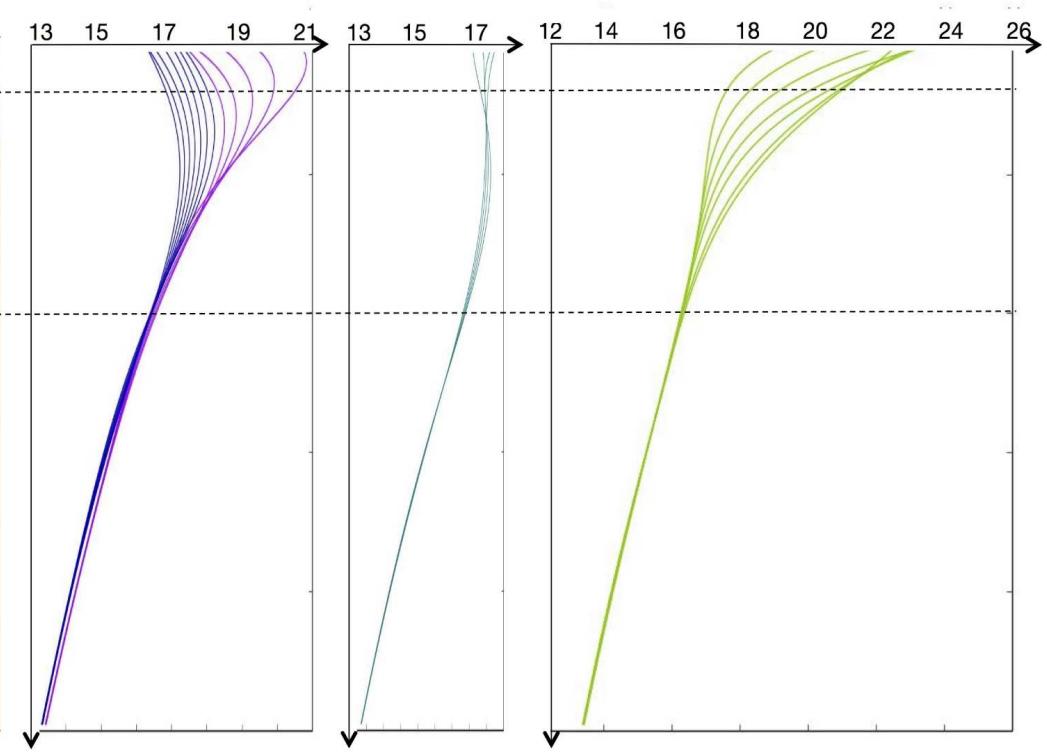

Figure 7: Three proposed node distributions (On the left-hand side the three node distributions, and on the right-hand side the temperature profiles obtained from the analytic solution.) (2 columns, print in color)

\section{Results}

444 4.1. Sensitivity study

Some assumptions made for the model parametrization may affect the sur446 face temperature calculation. Some authors carried out a sensitivity study 
on the surface and material parameters, on the convective heat transfer coefficient or on the grid size. However, none of these studies has compared the relative influence of all the affecting parameters.

In the following section, a model sensitivity study is performed on the surface temperature on June $5^{\text {th }}$ and $6^{\text {th }}$. Two kinds of parameters are used for this study: those used for the calibration step (soil thermal characteristics and the convective heat transfer coefficient) and two additional parameters which have been identified to be relevant: the deep boundary conditions and the size of the layers. Parameter sensitivity is studied regarding the order of magnitude of its uncertainty.

The sensitivity study is presented from the most influential parameter to the least influential: the convective heat transfer coefficient, followed by the material characteristics, the layer size, and the deep boundary condition.

\subsubsection{Convective heat transfer coefficient}

Several methods are presented to estimate the convective heat transfer coefficient $h$ in Section 3.1.2. Two methods are first compared to select the most suitable:

- MacAdams (1954, [27]) formula: linear function of the wind speed (coefficients $a$ and $b$ equal to 3.8 and 5.7 respectively).

- Correlation equation with dimensionless numbers and different characteristics length $(1,10,50 \mathrm{~m})$.

Figure 8 illustrates the comparison. For the correlation method, after calculating the dimensionless coefficients, the convection mode varies over time: 
it is mostly mixed during the night and forced during the day. Free convection is not represented by the first formula, whereas it is not integrated into the MacAdams formula. The correlation method is closer to the measured heat flux throughout the comparison period.

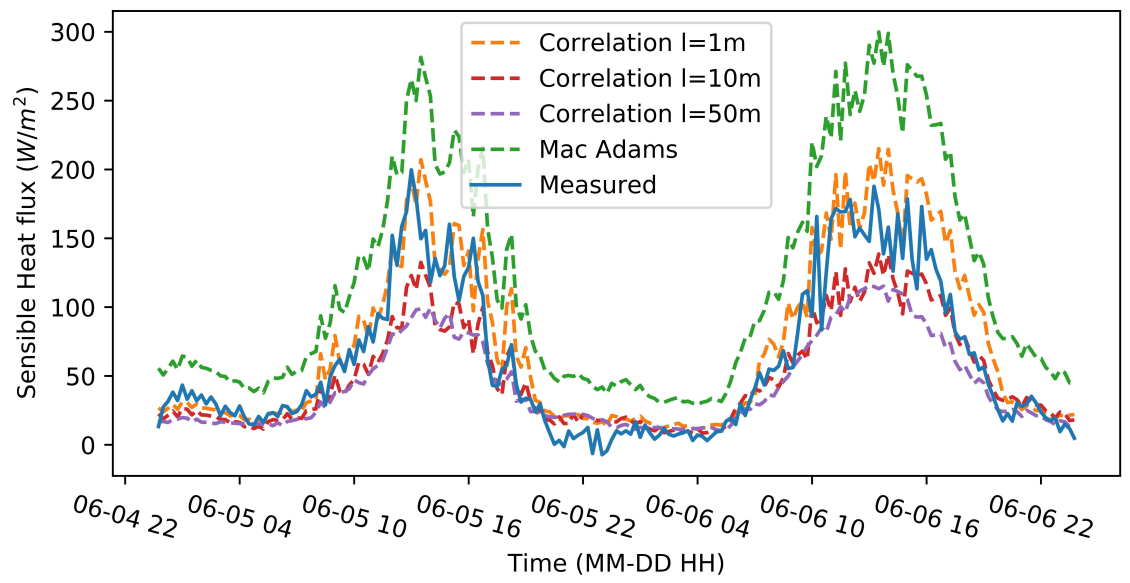

Figure 8: Comparison between the measured sensible heat fluxes at a height of $2 \mathrm{~m}$ and two calculation methods: the correlation method and the Mac Adams formula. (2 columns, print in color)

The correlation method used to calculate the convective heat transfer coefficient (Section 3.1.2), is based on results obtained by Tain and Petit (1989, [31]) applied for a horizontal flat plate. In order to apply the similitude theory, a characteristic length should be set which is most of the time defined as the distance from the leading edge. Applied to our case, this characteristic length is difficult to define. The influence of several lengths (1, 10 and $50 \mathrm{~m}$ ) is tested (Figure 8). Among the tree values tested, it appears that the 1m- characteristic length correlation method produces the lowest RMSE $\left(24.27 W \cdot m^{-2}\right)$. 
494

For each value, the correlation method remains better than the MacAdams method. As a result, for the following sub-sections, the correlation method is chosen with a characteristic length of $1 \mathrm{~m}$. The resulting convective heat transfer coefficient varies from 2.6 to $12.6 \mathrm{~W} \cdot \mathrm{m}^{-2} \cdot \mathrm{K}^{-1}$.

In order to see the influence of the characteristic length value on the sensible heat flux, the RMSE calculated with the 1m- characteristic length is compared to the daily mean sensible heat flux $\left(61 W \cdot m^{-2}\right)$. The RMSE represents $40 \%$ of the mean experimental value.

According to these levels of magnitude, we performed the sensitivity study varying the convective heat transfer coefficient up to $40 \%$ of its initial value. The aim is here to quantify the influence of this coefficient on the surface temperature. The results are presented in Table 8.

\begin{tabular}{lll}
\hline Indicator & $h+40 \%$ & $h-40 \%$ \\
\hline Maximum error $\left({ }^{\circ} \mathrm{C}\right)$ & 3.70 & 5.46 \\
Mean error $\left({ }^{\circ} \mathrm{C}\right)$ & 1.89 & 2.78 \\
RMSE $\left({ }^{\circ} \mathrm{C}\right)$ & 2.12 & 3.14 \\
\hline
\end{tabular}

Table 8: Influence of the convective heat transfer coefficient on the surface temperature (June $5^{\text {th }}$ and $6^{\text {th }}$ )

\subsubsection{Sensitivity of the layer definition}

Modification of soil thermal conductivity, soil density and the thickness of the layers is performed one by one for each layer. The magnitude of the modifications and the layers concerned by the modification are described 


\begin{tabular}{lll}
\hline Parameter & Modified layer & $\begin{array}{l}\text { Maximum difference at } \\
\text { the surface }\left({ }^{\circ} \mathbf{C}\right)\end{array}$ \\
\hline Thermal conductivity & 0 & $<0,1$ \\
$\lambda+-10 \%$ & 1 & $<0,7$ \\
& 2 & $<0,7$ \\
& 3 & $<0,1$ \\
\hline Density & 0 & $<0,07$ \\
$\rho+-5 \%$ & 1 & $<0,3$ \\
& 2 & $<0,3$ \\
& 3 & $<0,07$ \\
\hline Size of the layer & 1 & $<0,04$ \\
$e+-0,01 m$ & 2 & $<0,15$ \\
\hline
\end{tabular}
property change is also presented in this table.

Table 9: Influence of soil characteristics (June $5^{\text {th }}$ and $6^{\text {th }}$ )

in Table 9. The surface temperature modification caused by each material of the biggest layers (1 and 2) is investigated (Table 9).

The height of each soil layer is not constant over the depth. Each height is therefore roughly estimated. To evaluate this lack of accuracy, the influence (The biggest layers (1 and 2$)$ is investigated (Table 9$)$.

504 The temperature change associated with layer size modification has the same magnitude as that associated with soil property modification of layers 0 and 3. However, it is negligible compared to the temperature change associated with soil property modification of layers 1 and 2 . 


\subsubsection{Deep boundary condition}

The temperature imposed as a deep boundary condition may have an influence on the surface temperature. If the deep temperature is overestimated by one degree, the surface temperature increases by only $0.05^{\circ} \mathrm{C}$.

\subsection{Model ability to reproduce heat conduction transfer: validation}

The ability of the model to properly reproduce the physical phenomenon is evaluated in this section. In order to quantify the uncertainty due to the model itself (i.e. the accuracy of the physical phenomenon representation), the model is first evaluated comparing temperature estimation to experimental data. For this purpose, the model with a centimetric grid is used. As was noticed in Section 3.4, the evaluation of soil model performance based only on surface temperature comparison is one of the lacks identified in the literature. In this study, results are compared on the basis of the temperature at the surface and at several depths in the soil.

The model was evaluated during June $5^{t h}, 12^{\text {th }}$, and $13^{\text {th }}$. The model correctly reproduces the heat flux conduced into the different layers of the soil as shown in Figures 9 and 10. The maximum difference between the measured and simulated temperature at the surface is $1.67^{\circ} \mathrm{C}$, with an RMSE of $0.71^{\circ} \mathrm{C}$ for June $5^{\text {th }} ; 1.16^{\circ} \mathrm{C}$ with an RMSE of $0.60^{\circ} \mathrm{C}$ for June $12^{\text {th }}$ and $2.45^{\circ} \mathrm{C}$ with an RMSE of $1.28^{\circ} \mathrm{C}$ for June $13^{\text {th }}$. The mean daily RMSE between the estimated and the observed surface temperature is $0.86^{\circ} \mathrm{C}$, and $0.72^{\circ} \mathrm{C}, 0.58^{\circ} \mathrm{C}, 0.26^{\circ} \mathrm{C}$ and $0.13^{\circ} \mathrm{C}$ at $5 \mathrm{~cm}-, 10 \mathrm{~cm}-, 34 \mathrm{~cm}-$ and $50 \mathrm{~cm}$-depths respectively (June $5^{\text {th }}, 12^{\text {th }}$ and $13^{\text {th }}$ ). 


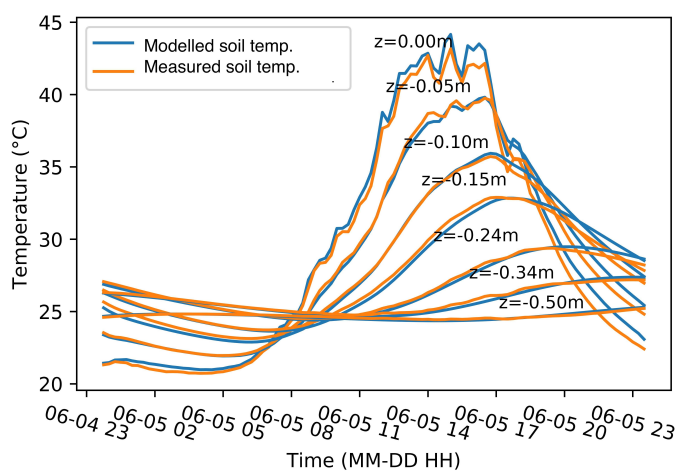

Figure 9: Comparison of simulated and measured temperatures at the surface and at several depths, June $5^{\text {th }}$ (1 column, print in color)

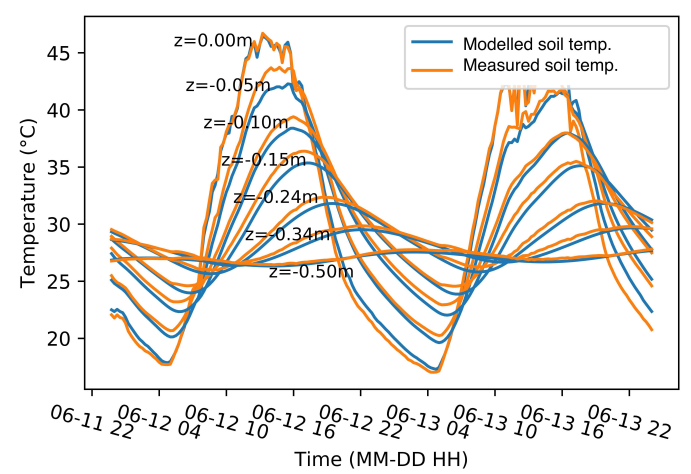

Figure 10: Comparison of simulated and measured temperatures at the surface and at several depths, on June $12^{\text {th }}$, and $13^{\text {th }}$ (1 column, print in color)

To quantify the accuracy of the model in reproducing the temperature variation at several depths, Qin (2002, [22]) divide the RMSE by the amplitude of the signal. In fact, as the amplitude decreased, the relative error increased. Going deeper in the ground the amplitude decreased with the RMSE but in proportion this error increased. In fact, at the surface, the RMSE represents only between $10 \%$ to $4.7 \%$ of the amplitude, while at a depth of $34 \mathrm{~cm}$ and $50 \mathrm{~cm}$ it represents between $6 \%$ to $11.7 \%$ and between $8.9 \%$ to $104.7 \%$ respectively. The error remains under the uncertainty of the temperature measurement.

\subsection{Influence of node distribution}

The ability of the model to reproduce the physical phenomenon (centimetric grid model compared to the experimental data) is compared to the accuracy loss due to the reduction of the number of nodes. Table 11 presents 


\begin{tabular}{|c|c|c|c|c|}
\hline \multirow[b]{2}{*}{ Date } & \multirow[b]{2}{*}{ Depth } & \multicolumn{2}{|l|}{ Maximum } & \multirow[b]{2}{*}{ RMSE/amplitude } \\
\hline & & $\begin{array}{l}\text { absolute error } \\
\left({ }^{\circ} \mathrm{C}\right)\end{array}$ & RMSE $\left({ }^{\circ} \mathbf{C}\right)$ & \\
\hline \multirow[t]{5}{*}{ June $5^{t h}$} & Surface & 1.67 & 0.71 & 0.032 \\
\hline & $5 \mathrm{~cm}$ & 0.93 & 0.43 & 0.024 \\
\hline & $10 \mathrm{~cm}$ & 0.69 & 0.36 & 0.028 \\
\hline & $34 \mathrm{~cm}$ & 0.35 & 0.15 & 0.060 \\
\hline & $50 \mathrm{~cm}$ & 0.14 & 0.07 & 0.089 \\
\hline \multirow[t]{5}{*}{ June $12^{t h}$} & Surface & 1.16 & 0.60 & 0.020 \\
\hline & $5 \mathrm{~cm}$ & 1.91 & 0.94 & 0.040 \\
\hline & $10 \mathrm{~cm}$ & 1.01 & 0.73 & 0.045 \\
\hline & $34 \mathrm{~cm}$ & 0.58 & 0.317 & 0.095 \\
\hline & $50 \mathrm{~cm}$ & 0.20 & 0.11 & 0.1 \\
\hline \multirow[t]{5}{*}{ June $13^{t h}$} & Surface & 2.45 & 1.28 & 0.047 \\
\hline & $5 \mathrm{~cm}$ & 1.42 & 0.79 & 0.024 \\
\hline & $10 \mathrm{~cm}$ & 1.00 & 0.66 & 0.028 \\
\hline & $34 \mathrm{~cm}$ & 0.57 & 0.33 & 0.117 \\
\hline & $50 \mathrm{~cm}$ & 0.3 & 0.22 & 0.247 \\
\hline
\end{tabular}

Table 10: Evaluation of the centimetric grid model according to the experimental data

544 the total error due to the model and node distribution (first and third line) 545 and the part of the error which is due to the reduction in the number of 546 nodes (second and fourth line). 


\begin{tabular}{|c|c|c|c|c|c|}
\hline Date & Model & $1 \mathrm{pt} / \mathrm{cm}$ & $8 / 10 / 4$ & $4 / 6 / 2$ & $4 / 3 / 2$ \\
\hline \multirow[t]{2}{*}{ June $5^{t h}$} & $\begin{array}{l}\text { RMSE with experimental } \\
\text { data }\left({ }^{\circ} \mathrm{C}\right)\end{array}$ & 0.71 & 0.71 & 0.65 & 0.65 \\
\hline & $\begin{array}{l}\text { RMSE with centimetric grid } \\
\left({ }^{\circ} \mathrm{C}\right)\end{array}$ & - & 0.03 & 0.13 & 0.36 \\
\hline \multirow[t]{2}{*}{ June $12^{t h}$} & $\begin{array}{l}\text { Root mean square error } \\
\text { with experimental data }\left({ }^{\circ} \mathrm{C}\right)\end{array}$ & 0.60 & 0.62 & 0.65 & 0.85 \\
\hline & $\begin{array}{l}\text { RMSE with centimetric grid } \\
\left({ }^{\circ} \mathrm{C}\right)\end{array}$ & - & 0.03 & 0.15 & 0.42 \\
\hline \multirow[t]{2}{*}{ June $13^{t h}$} & $\begin{array}{l}\text { RMSE with experimental } \\
\text { data }\left({ }^{\circ} \mathrm{C}\right)\end{array}$ & 1.28 & 1.30 & 1.10 & 1.26 \\
\hline & $\begin{array}{l}\text { RMSE with centimetric grid } \\
\left({ }^{\circ} \mathrm{C}\right)\end{array}$ & - & 0.03 & 0.44 & 0.60 \\
\hline
\end{tabular}

Table 11: Evaluation of the model with a reduced numbers of nodes 


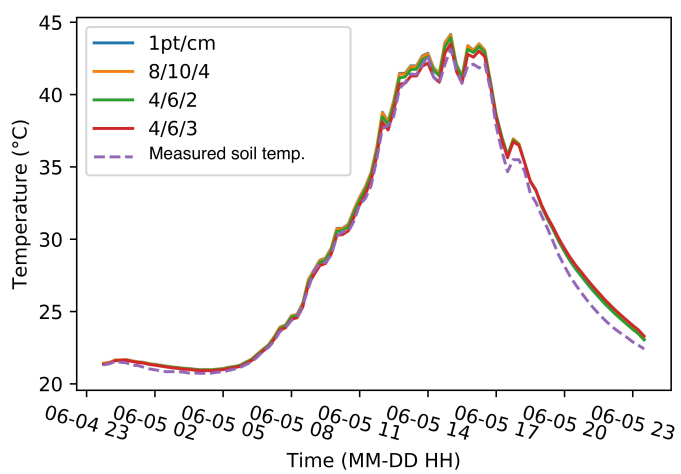

Figure 11: Surface temperature calculated with the different grids compared to that measured (June $\left.5^{\text {th }}\right) \cdot(1$ column, print in color)

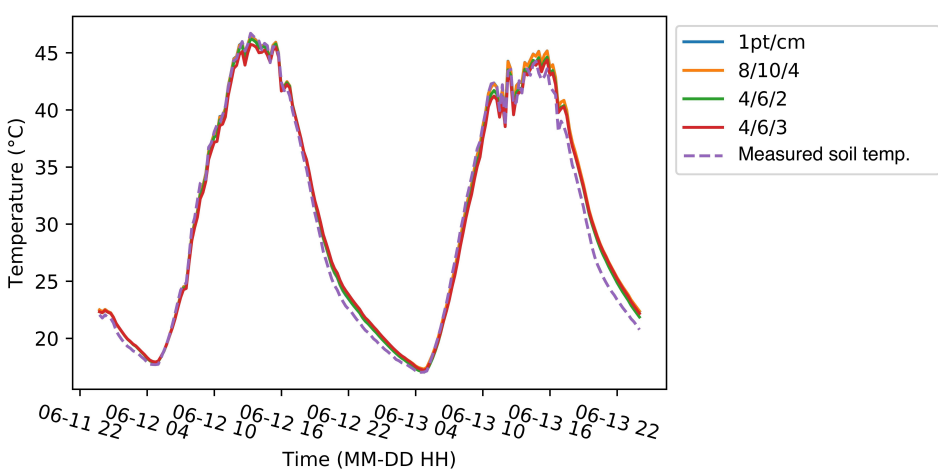

Figure 12: Surface temperature calculated with the different grids compared to that measured (June $12^{\text {th }}$ and $\left.13^{\text {th }}\right)$.(1 column, print in color)

and minimum peak are slightly underestimated.

The underestimated daily maximum peak and minimum trough are due to the reduction in the number of nodes that worsens the representation of the heat transfer into the ground. In fact, this induces a time shift of heat conduction, the main influence of which appears when its sign changes.

For the $4 / 6 / 2$ and for the $4 / 3 / 2$ node model, the accuracy loss due to the reduction in the number of nodes remains lower than the model accuracy (centimetric grid RMSE). The absolute error of the model is sometimes lower using these node distributions than the centimetric distribution. The reason is that the model itself overestimates the surface temperature whereas as a lower number of nodes underestimates it (Figures 11 and 12 ).

Finally, the reduction of the number of nodes has consequences on the reproduction of the daily peaks. This confirms that the correct representation 
569

570

571

572

573

574

575

576

577

578

of the surface temperature requires that the heat flux transfer into the soil be correctly represented.

\section{Discussion}

This part is devoted to discussing the overall accuracy of the model. The results are firstly compared to those presented in the literature. The accuracy of the model according to meteorological data is then evaluated with an annual simulation.

\subsection{Comparison with other models accuracy}

The performance of the models presented above may be compared to the performance of other models. From the literature the results of the following authors are chosen: Yang et al. (2013 [5]), Herb et al. (2008 [13]), Best (1998 [9]) , Malys, (2012 [32, 7]). Note that Malys, $(2015,[32,7])$ applied the model proposed by Bouyer (2009, [4]). Those models are chosen because their simulation conditions (weather conditions, node distribution, type of ground surface, indicator calculated for performance evaluation) are the closest to those of the present study. Conditions of simulation and results are summarized in Table 12.

Three of the four articles $([5,9,13])$ have in common the type of surface studied and a gradual distribution of nodes: thinner at the surface than bellow. The last one, Malys $(2012,[32,7])$, evaluated the previous SOLENEmicroclimat soil model with a grass surface and a mesh with only 4 nodes. 
590 Simulations are run during the summer period during sunny days with

591

592 scattered clouds. The surface temperature rises from $41^{\circ} \mathrm{C}$ to $70^{\circ} \mathrm{C}$, except for Best (1998, [9]), who worked with a lower temperature.

According to the results presented in Table 12, the centimetric grid model is more accurate than the other models from the literature. This is a logical result as the centimetric model uses a high number of nodes.

Using a grid with 15 nodes, Herb et al. (2008 [13]) obtained lower performances $\left(1.58^{\circ} \mathrm{C}\right)$ than our model. The application conditions being similar, it can be affirmed that our model is at least as accurate as that of Herb et al. (2008 [13]) but with more optimized discretization. The difference in performance can mainly be explained by thinner discretization near the surface. 


\begin{tabular}{|c|c|c|c|c|c|c|}
\hline Article & Surface type & $\begin{array}{l}\text { Meteorological con- } \\
\text { ditions }\end{array}$ & $\begin{array}{l}\text { Maximum surface } \\
\text { temperature }{ }^{\circ} \mathrm{C}\end{array}$ & Amplitude & $\begin{array}{l}\text { Numerical } \\
\text { discretization }\end{array}$ & $\mathrm{RMSE}^{\circ} \mathrm{C}$ \\
\hline \multirow[t]{2}{*}{ Best (1998, [9]) } & Asphalt & Winter conditions & - & - & 20 nodes & 1.08 \\
\hline & Concrete & & 12 & 18 & & 1.2 \\
\hline Herb and al. (2008, [13]) & Asphalt & Hot and Dry (July) & 55 & $<30$ & 15 nodes & 1.58 \\
\hline Malys (2012, [32]) & Grass & Hot and Dry (May) & 41 & 19 & 4 nodes & 2.3 \\
\hline Yang and al. $(2013,[5])$ & $\begin{array}{l}\text { Tiles, concrete, } \\
\text { asphalt, paved, } \\
\text { grass }\end{array}$ & Hot and Dry (August) & 70 & 40 & 14 nodes & 1.98 \\
\hline \multirow[t]{4}{*}{ Presented here } & Asphalt & Heat wave conditions & 50 & 30 & 100 nodes & 0.86 \\
\hline & & & & & $\begin{array}{l}8 / 10 / 4: \\
\text { nodes }\end{array}$ & 0.87 \\
\hline & & & & & 4/6/2: 12 nodes & 0.80 \\
\hline & & & & & 4/3/2: 9 nodes & 0.92 \\
\hline
\end{tabular}

Table 12: Comparison with the other models: simulation conditions 
Yang et al. (2013, [5]) presented a 14-layer model with $1.98^{\circ} \mathrm{C}$ accuracy which is lower than all the models evaluated in this paper. Nevertheless, it is applied to extreme conditions: the maximum surface temperature may reach $70^{\circ} \mathrm{C}$ with a daily variation whose amplitude reaches $40^{\circ} \mathrm{C}$.

For similar surface temperature amplitudes $\left(<30^{\circ} \mathrm{C}\right.$ and $40^{\circ} \mathrm{C}$ respectively ), Herb et al. (2008 [13]) and Yang et al. (2013, [5]) obtained an RMSE of $1.58^{\circ} \mathrm{C}$ and $1.98^{\circ} \mathrm{C}$ respectively.

The model presented by Malys (2012, [32]) has only 4 nodes whereas the other models have more than 14 nodes. Consequently, it is the least accurate one, even though the model is applied with fair solicitations: a low amplitude of surface temperature variation $\left(19^{\circ} \mathrm{C}\right)$ and low maximum temperature $\left(41^{\circ} \mathrm{C}\right)$. Using a higher number of nodes with good distribution seems to be essential to obtain good performance. However, this result should be treated with caution since Malys (2012, [32]) does not use the same ground surface type as the other authors.

Two of the authors highlight that the high amplitude of surface temperature recorded during the day is harder to represent than the surface temperature during the night. Yang et al.(2013, [5]) described the fact that the model fits well with the measurement at night time and in the morning, but when the temperature rises during the afternoon the model underestimates the temperature with an average o3.5 C. Best (1998, [9]) also has better results during the night $\left(\mathrm{RMSE} 0.83^{\circ} \mathrm{C}\right)$ than during the day (RMSE $1.26^{\circ} \mathrm{C}$ ). This analysis is consistent with the assumption made previously: clear, hot days, characterized by high surface temperature amplitude, are 
the most difficult days to simulate.

In general, one needs to exercise care in considering the results of this comparison for several other reasons:

- the surface temperature used as the reference temperature for each study comes from surface temperature measurement. Uncertainty on such measurement might be of the same magnitude as the RMSE observed, which makes comparisons between models difficult.

- the comparison of the model's performance is given for studies in similar conditions. Nevertheless, they cannot be exactly the same. The location is not the same, the weather conditions differ, and the surface type or at least the soil composition is not exactly the same.

Even though we conclude that the models proposed in this paper seem to present better performance than those of the literature, the difference must be put into perspective with application conditions. All those models should be applied to a single case study.

\subsection{Performance according to meteorological data}

The accuracy of the different grids according to meteorological data is evaluated comparing numerical profile of an annual simulation (hourly time step) for each node distribution $(8 / 10 / 4,4 / 6 / 2,4 / 3 / 2)$. For those simulations, meteorological data recorded during one year (2010) at the Pin Sec station in the city of Nantes are used. These data were collected by the 


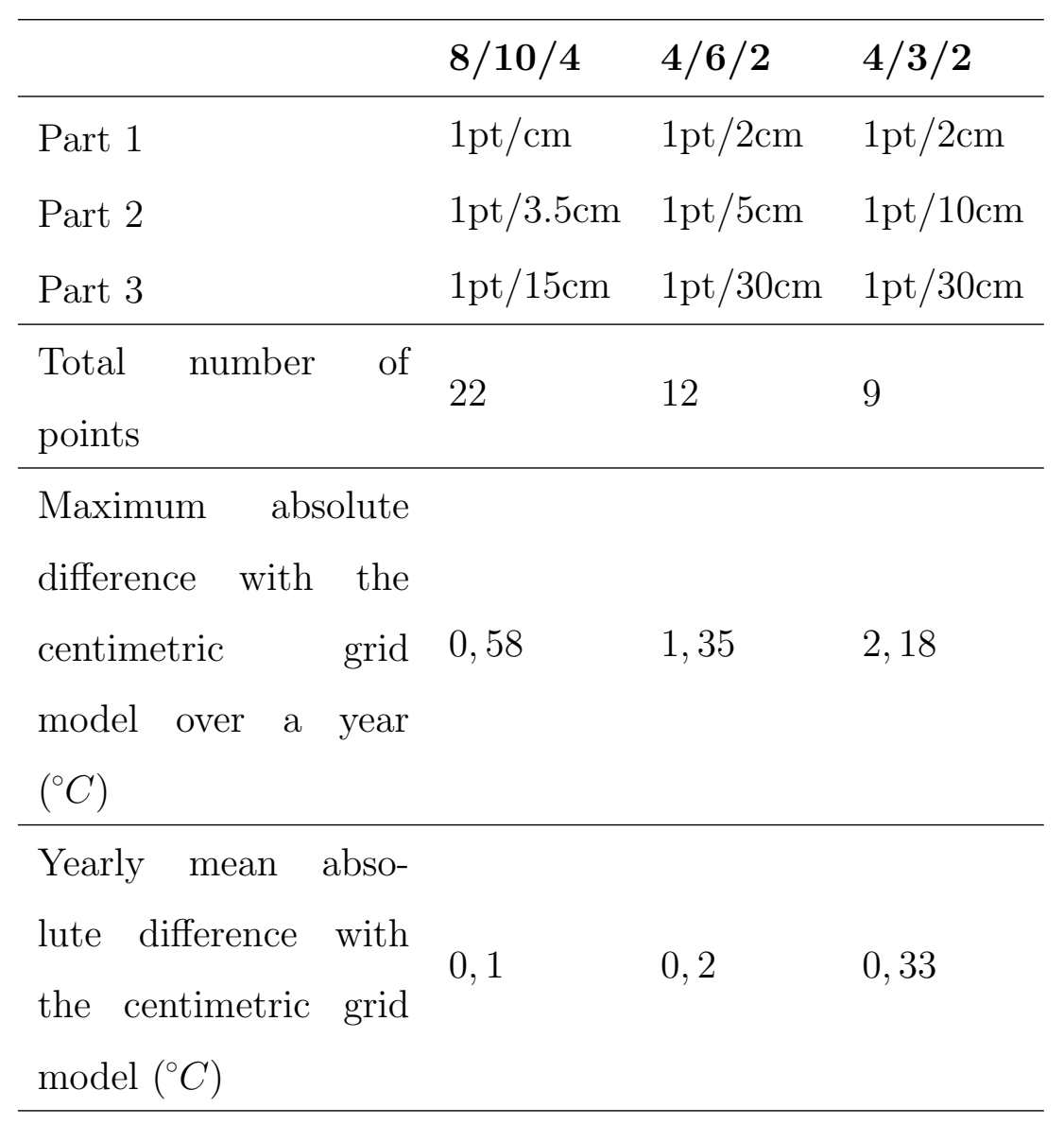

Table 13: Distribution of the nodes and accuracy ronment observatory of the IRSTV [33]). Among the available observations, the following data are used as input in the model: air temperature, pressure and humidity, global and IR radiative flux, and wind velocity and direction.

ONEVU (Observatoire Nantais des EnVironnements Urbains - urban envi-

Table 13 presents the results of the comparison between the surface temperature model for each of the node distribution compared to the centimetric grid model. In the case of the $8 / 10 / 4$ nodes model, the maximum absolute 
difference is $0.58^{\circ} \mathrm{C}$ and for the $4 / 3 / 2$ node model, $2.18^{\circ} \mathrm{C}$. The mean absolute difference for the first node distribution is only $0.1^{\circ} \mathrm{C}$ whereas that of the $4 / 3 / 2$ distribution is $0.33^{\circ} \mathrm{C}$, which remains in the order of magnitude of the measurement uncertainty.

For each case, the frequency of appearance of the mean daily error between the centimetric grid and the reduced grid model is calculated. Each day is ranked in a different performance class to illustrate the differences between the node distribution (Table 14).

\begin{tabular}{llll}
\hline Mean daily error & Low $: E<0.2$ & Medium: $0.2<E<0.5$ & High $E>0.5$ \\
\hline $8 / 10 / 4$ & 363 & 2 & 0 \\
$4 / 6 / 2$ & 212 & 150 & 3 \\
$4 / 3 / 2$ & 82 & 224 & 59 \\
\hline
\end{tabular}

Table 14: Number of days for which each class of error occurs (error calculated compared the centimetric grid model)

The 8/10/4 node model does not have any day with a mean error higher than $0.5^{\circ} \mathrm{C}$ and has only two days with a mean error higher than $0.2^{\circ} \mathrm{C}$. The 4/6/2 node model has almost as many days represented with high or medium performance. Finally, most of the days represented by the $4 / 3 / 2$ node model have medium performance. More detailed investigation of the days with high mean daily error shows that these days were clear and sunny ones. This confirms the fact that clear days are more difficult to simulate than cloudy days. 


\section{Conclusion}

The main purpose of this study is to propose a model that accurately reproduces the heat storage flux into urban ground as well as changes in surface temperature.

Some failings were identified in the literature review, pointing up the need:

- to perform an overall sensitivity analysis,

- to investigate the advantage of using different convection flow modes (forced, mixed, natural)

- to justify the chosen mesh,

- to assess models not only for surface temperature calculation.

To test the robustness of our model regarding its parameters, a complete sensitivity study was carried out on the model parameters: all have a negligible impact except the convective heat transfer coefficient.

Special attention has been paid to how the convective heat transfer coefficient is calculated. The chosen method makes it possible to take into account the different kinds of convection flow modes which is necessary for an urban application. Nevertheless, the sensitive heat flux can vary by $40 \%$, leading to an uncertainty up to $3.14^{\circ} \mathrm{C}$ on the surface temperature RMSE.

After calibration of the different parameters, soil model (using a centimetric grid) accuracy is evaluated according to a measurement campaign carried 
out in a large asphalt car park during three sunny days with scattered clouds. The RMSE between estimated and observed temperatures is calculated for surface temperature and ground temperature at several depths. Surface temperature RMSE is $0.86^{\circ} \mathrm{C}$; RMSE for temperature at $34 \mathrm{~cm}$ of depth is $0.26^{\circ} \mathrm{C}$. The results validate the ability of the model to reproduce heat storage into the ground.

Three node distributions are proposed on the basis of the analysis of the different temperature profiles throughout the depth. They all are dedicated to any kind of impervious urban surfaces. However, for less diffusive soils, the user is free to define other distributions in order to adapt the model to his application. The accuracy of the models varies from $0.62^{\circ} \mathrm{C}$ to $1.30^{\circ} \mathrm{C}$. These performances are better than those of models from the literature applied under quite similar conditions.

Finally, application of the models over a whole year shows that only a few days are represented with an accuracy worse than $0.5^{\circ} \mathrm{C}$. Most days are even reproduced with an accuracy better than $0.2^{\circ} \mathrm{C}$. The investigation demonstrates that surface temperatures during clear and sunny days are the most difficult to reproduce.

This paper provides a complete overview of soil model performance, comparing it with experimental data, centimetric grid model, and literature results. Because of measurement uncertainty, better performances would be difficult to obtain and especially to assess. Nevertheless, comparison of the model performances with results from the literature would require a benchmark. The model presented, now validated, is ready to include moisture 
transfer and in particular the evaporation of water at the soil surface, to help to properly assess the effect on local climate and outdoor comfort of moistening techniques.

\section{Acknowledgements}

This research work was carried out within the scope of the EVA Project, funded by the ADEME (French Environment and Energy Management Agency) under Contract No. 1216C0037. The authors are grateful to the ADEME and Véolia for their financial support of this study, as well as to IFSTTAR, LHEEA and ONEVU for providing us with the experimental data.

\section{References}

[1] T. R. Oke, Boundary layer climates, Routledge, 2002.

[2] V. Masson, A physically-based scheme for the urban energy budget in atmospheric models, Boundary-layer meteorology 94 (2000) 357-397.

[3] R. Tavares, I. Calmet, S. Dupont, Modelling the impact of green infrastructures on local microclimate within an idealized homogeneous urban canopy, in: ICUC9-9th International Conference on Urban Climate jointly with 12th Symposium on the Urban Environment Modelling, pp. $1-6$.

[4] J. Bouyer, Modelisation et simulation des microclimats urbains-Etude de l'impact de l'amenagement urbain sur les consommations energetiques des batiments, Ph.D. thesis, Universite de Nantes, 2009. 
[5] X. Yang, L. Zhao, M. Bruse, Q. Meng, Evaluation of a microclimate model for predicting the thermal behavior of different ground surfaces, Building and Environment 60 (2013) 93-104.

[6] A. Gros, Modélisation de la demande énergétique des bâtiments à l'échelle d'un quartier, Ph.D. thesis, Université de La Rochelle, 2013.

[7] M. Musy, L. Malys, B. Morille, C. Inard, The use of solene-microclimat model to assess adaptation strategies at the district scale, Urban Climate $14(2015)$ 213-223.

[8] T. Asaeda, V. T. Ca, The subsurface transport of heat and moisture and its effect on the environment: a numerical model, Boundary-Layer Meteorology 65 (1993) 159-179.

[9] M. Best, A model to predict surface temperatures, Boundary-Layer Meteorology 88 (1998) 279-306.

[10] M. Best, P. Cox, D. Warrilow, Determining the optimal soil temperature scheme for atmospheric modelling applications, Boundary-layer meteorology 114 (2005) 111-142.

[11] T. T. Chow, H. Long, H. Mok, K. Li, Estimation of soil temperature profile in hong kong from climatic variables, Energy and Buildings 43 (2011) 3568-3575.

[12] B. K. Diefenderfer, I. L. Al-Qadi, S. D. Diefenderfer, Model to predict pavement temperature profile: development and validation, Journal of Transportation Engineering 132 (2006) 162-167. 
[13] W. R. Herb, B. Janke, O. Mohseni, H. G. Stefan, Ground surface temperature simulation for different land covers, Journal of Hydrology 356 (2008) 327-343.

[14] Å. Hermansson, Mathematical model for calculation of pavement temperatures: comparison of calculated and measured temperatures, Transportation Research Record: Journal of the Transportation Research Board (2001) 180-188.

[15] D. Ho, A soil thermal model for remote sensing, IEEE transactions on geoscience and remote sensing (1987) 221-229.

[16] C. Jacovides, G. Mihalakakou, M. Santamouris, J. Lewis, On the ground temperature profile for passive cooling applications in buildings, Solar energy 57 (1996) 167-175.

[17] J. Lin, On the force-restore method for prediction of ground surface temperature, Journal of Geophysical Research: Oceans 85 (1980) 32513254 .

[18] G. Mihalakakou, M. Santamouris, J. Lewis, D. Asimakopoulos, On the application of the energy balance equation to predict ground temperature profiles, Solar Energy 60 (1997) 181-190.

[19] G. Mihalakakou, On estimating soil surface temperature profiles, Energy and Buildings 34 (2002) 251-259.

[20] H. Nowamooz, S. Nikoosokhan, J. Lin, C. Chazallon, Finite difference modeling of heat distribution in multilayer soils with time-spatial hydrothermal properties, Renewable Energy 76 (2015) 7-15. 
[21] O. Ozgener, L. Ozgener, J. W. Tester, A practical approach to predict soil temperature variations for geothermal (ground) heat exchangers applications, International Journal of Heat and Mass Transfer 62 (2013) $473-480$.

[22] Z. Qin, P. Berliner, A. Karnieli, Numerical solution of a complete surface energy balance model for simulation of heat fluxes and surface temperature under bare soil environment, Applied mathematics and computation 130 (2002) 171-200.

[23] H. Saito, J. Simunek, Effects of meteorological models on the solution of the surface energy balance and soil temperature variations in bare soils, Journal of Hydrology 373 (2009) 545-561.

[24] H. Swaid, M. E. Hoffman, The prediction of impervious ground surface temperature by the surface thermal time constant (sttc) model, Energy and Buildings 13 (1989) 149-157.

[25] J. Palyvos, A survey of wind convection coefficient correlations for building envelope energy systems' modeling, Applied Thermal Engineering 28 (2008) 801-808.

[26] T. Defraeye, B. Blocken, J. Carmeliet, Convective heat transfer coefficients for exterior building surfaces: Existing correlations and cfd modelling, Energy Conversion and Management 52 (2011) 512-522.

[27] W. H. McAdams, Heat transmission, 3rd, New York (1954).

[28] B. Morille, Élaboration d'un modèle du climat distribué à l'échelle de l'abri et de la plante en cultures ornementales sous serres: analyse des 
transferts de masse et de chaleur, bilans énergétiques, Ph.D. thesis, Agrocampus-Centre d'Angers, 2012.

[29] J. Cohard, J. Rosant, F. Rodriguez, H. Andrieu, P. Mestayer, P. Guillevic, Energy and water budgets of asphalt concrete pavement under simulated rain events, Under Review in Urban Climate (2017).

[30] Q. Xu, M. Solaimanian, Modeling temperature distribution and thermal property of asphalt concrete for laboratory testing applications, Construction and building materials 24 (2010) 487-497.

[31] J. Taine, J.-P. Petit, R. Séméria, J.-P. Petit, Transferts thermiques: mécanique des fluides anisothermes: cours et données de base, Dunod, 1989.

[32] L. Malys, Évaluation des impacts directs et indirects des façades et des toitures végétales sur le comportement thermique des bâtiments, Ph.D. thesis, PhD thesis] Ecole Centrale de Nantes (France), 2012.

[33] P. Mestayer, J. Rosant, F. Rodriguez, J. Rouaud, The experimental campaign fluxsap 2010: climatological measurements over a heterogeneous urban area, Int Assoc Urb Climate 40 (2011) 22-30. 